\title{
Aerobic Interval Training in Freestyle Swimming
}

\author{
Edi Wahyudi M', Yudi Hendrayana, ${ }^{2, *}$, Amung Ma'mun², Boyke Mulyana² \\ ${ }^{1}$ Faculty of Education, Institut Agama Islam Negeri (IAIN) Curup, Indonesia \\ ${ }^{2}$ Faculty of Sports Education, Indonesian University of Education, Indonesia
}

Received June 9, 2020; Revised July 29, 2020; Accepted August 10, 2020

\section{Cite This Paper in the following Citation Styles}

(a): [1] Edi Wahyudi M, Yudi Hendrayana, Amung Ma'mun, Boyke Mulyana, "Aerobic Interval Training in Freestyle Swimming," International Journal of Human Movement and Sports Sciences, Vol. 8, No. 4, pp. 142 - 146, 2020. DOI: 10.13189/saj.2020.080406.

(b): Edi Wahyudi M, Yudi Hendrayana, Amung Ma'mun, Boyke Mulyana (2020). Aerobic Interval Training in Freestyle Swimming. International Journal of Human Movement and Sports Sciences, 8(4), 142 - 146. DOI: 10.13189/saj.2020.080406.

Copyright@2020 by authors, all rights reserved. Authors agree that this article remains permanently open access under the terms of the Creative Commons Attribution License 4.0 International License

\begin{abstract}
This research was conducted so that the endurance and speed of swimming athletes can be increased and prepare young swimmers to be able to reach the time requirements in following the provincial championship. Problems found in the field, athletes train in the conventional way, and training programs are arranged based on the trainer's experience. This is the basis for the use of aerobic interval training for young swimmers because it can form training early by using a proven theoretical basis that can increase the time in swimming. The research began by revealing the ability of the freestyle athlete in the swimming club through aerobic interval training in order to have maximum endurance and speed. This training involved 18 athletes in the age range of 10-15 years. The success of the training is known through data obtained from the best time during aerobic training in the $50 \mathrm{~m}$ freestyle swimming. Swimming time measurement uses a stopwatch so that freestyle swimming time is known before and after training. Time achievement that has been obtained is done different tests to see the effect of interval training on swimming time speed. The final measurement results show that the athlete's time achievement in freestyle swimming changes after being given aerobic interval training. The results of this study will support the achievement of best time young swimmers to take part in the National Sports Week by continuing training using theoretically and empirically tested training programs.
\end{abstract}

Keywords Freestyle Swimming, Aerobic Interval Training

\section{Introduction}

Youth swimming athletes are assets that need to be developed to their full potential early in order to be able to carve out achievements. The competency development of swimming athletes will contribute greatly to the club and region that sent it so that various trainings need to be done. Competition between clubs, schools and regions is one of the barometers of athlete achievement in getting the best time after practicing before competing. The athlete's achievement in each competition is expected to increase in order to reach the minimum time limit and is a requirement to attend a national and even international sports week.

There are quite a lot of swimming clubs in Bengkulu Province and in every district. This condition illustrates that students who have talent in swimming can channel it through the existing swimming club. However, 2016 data show that Bengkulu province athletes who can meet the time requirements to attend the national sports week are only one person. This empirical fact is an evaluation material for swimming clubs and local governments. Factors causing the aspects of athletes, coaches and training programs that have been implemented to need to be evaluated, so that the best time achievements of athletes can meet the standards of a competition and obtain maximum performance. Observations at several swimming clubs show that athletes train in the conventional way, and training programs are arranged based on the experience of the majority of former athletes. Field findings form the basis for researchers to develop programs and implement aerobic interval training designed based on theoretical and empirical studies that have been proven to increase the 
time in swimming.

Interval training is a type of exercise that involves a series of high-intensity exercises interspersed with periods of rest. The intensity of the training will familiarize the heart muscle, provide cardiovascular exercise, increase aerobic capacity and allow for longer exercise at a more intense level [1]. Interval training can be identified in the type of intermittent training that manipulates the amount, intensity and duration of work attacks and the amount of recovery, which is used to produce certain types of stress on the body [2].

The application of interval training or continuous training can increase aerobic and anaerobic metabolism [3] which can burn more calories in a shorter period, and increase aerobic ability at a faster rate [4]. For those athletes who are capable, they need to improve endurance performance through high intensity interval training [5] [6] [3], because a regulated contribution by aerobic and anaerobic metabolism can improve endurance performance to a greater extent than continuous submaximal exercise alone [3], [7], [8]. Endurance training can also increase stroke volume and affect the delivery of oxygen to the muscles that work during high-intensity exercises performed [9]. This condition strengthens the data that skilled athletes need to be given high-level interval training so that they can increase endurance and speed in swimming, which impacts on the expected achievement.

Trainers have long used high-intensity training to improve the endurance performance of their elite athletes [10]. Training is usually achieved through the use of intervals. High-intensity training can be broadly defined as the repetition of short or moderate duration training items, die at a duration of 10 seconds to 5 minutes completed with an intensity greater than the anaerobic threshold [11] The aim of this training is to emphasize the physiological system in order to obtain certain resistance when exercising through repetitive activities [2]. A significant advantage of high-intensity training is the simultaneous regulation of oxidative and glycolytic energy systems resulting in an increase in energy acting on the muscles through the preservation of high-energy phosphates. Even observations show that trained individuals tend to respond better to higher intensity exercises [11]

In addition, high-intensity training results in more efficient muscle contraction and increased physical work capacity. Endurance training that is habitual can increase the volume of training that usually does not occur [12], [13], [14],[15]. Even high-intensity interval training that continues to be used, has been shown to have positive results in improving performance and physiological benefits [16]

The result of theoretical and empirical studies of the aerobic interval training show that researcher's practice is focused on the $50 \mathrm{~m}$ freestyle swimming sport. This training was conducted to spur the endurance and speed of time of athletes in order to prepare themselves and meet national competition time standards. Conventional and monotonous $\mathrm{S}$ training programs are replaced by variations in movement and distances that are as high in the recovery process. The four swimming style cross-training exercises are integrated in the training but still the composition of the freestyle swimming is greater. Physical training on land is done so that the formation of muscular endurance can support when training in water later. The implementation of this interval training involves beginners that are capable athletes. Athletes in swimming clubs do regular exercise according to a predetermined schedule. Interval training is given so that athletes have maximum endurance and speed in participating in competitions and are able to excel

\section{Method}

The approach used in this study is quantitative, with an experimental method. Interval training was carried out in 16 sessions in freestyle swimming. Determination of research subjects using purposive sampling, namely athletes who are in the swimming club and achievers at the school or regional level. The athletes are elementary and middle school students covered in the swimming club managed by the private sector. The selection of research subjects is aimed at training the endurance and speed of athletes in order to gain an increase in training or in competition later.

The research subjects are age groups in the age range of $10-15$ years as many as 18 people. This range includes the age of early adolescents [17]. Data collection technique is done by measuring the swimming time before being given treatment by using a stopwatch. Exercise is done as much as four days a week with a duration of time of three hours / day. Each meeting session was conducted cross style training but was more focused on freestyle. Training for 16 sessions was fully followed by swimmers. The exercise includes doing hand and foot movements separately and coordination as a whole. The end of the sprint training is done with multi-level distances ranging from $25 \mathrm{~m}, 50 \mathrm{~m}$, $100 \mathrm{~m}, 200 \mathrm{~m}, 300 \mathrm{~m}$ and $400 \mathrm{~m}$ followed by a $1-2$-minute recovery process between sprint distances.

Implementation of physical training for athletes is not only done in water but is complemented by physical training on land namely running, push ups, sit ups, back ups, full ups, squat thrust, agility, flexibility and weight training that supports swimming. Activities carried out eight meetings. As a whole, the training was held within two months and ended with measurement after being given a treatment. The results of the posttest measurements were compared with the pretest scores so it was known the effect of the implementation of interval training through the acquisition of the 50-meter freestyle swimming test results. 


\section{Results}

The results of data processing explained that the endurance and speed of athletes had increased namely the highest time achievement of athletes before being given training at a score of 34 seconds and the lowest time obtained 1 minute 14 seconds, whereas after being given training the fastest time interval reached 33 seconds, and the time delay was 1 minute 10 seconds. With complete data unraveled as the following graph 1 :

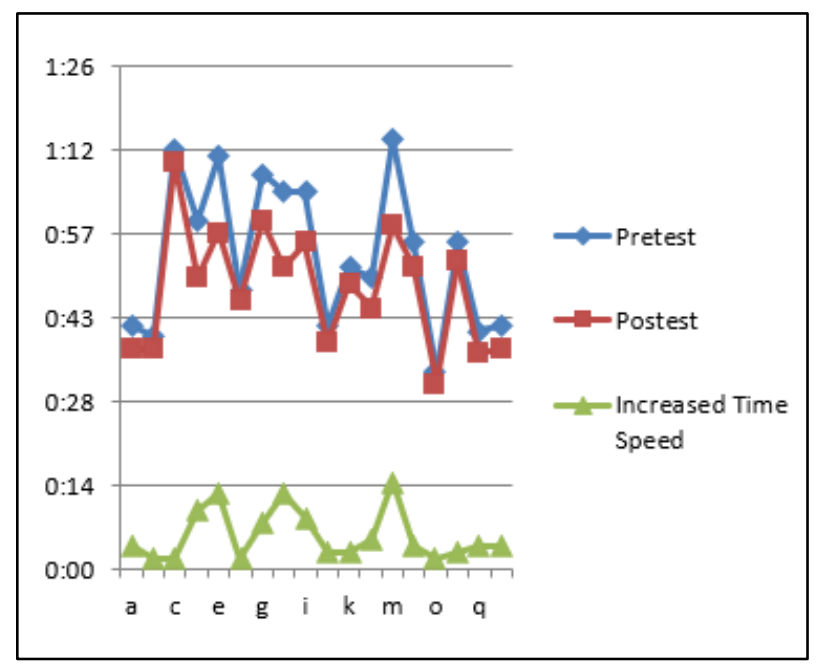

Graph 1. Obtaining Time Before and After Conducting Training

The graph explains the change in time for each athlete after 16 sessions of training are carried out. The acquisition of time changes shows an increase in 50-meter freestyle swimming speed. To test the increase in time obtained, a correlation test and a different test were performed, namely the Paired Samples t-Test in Table 1.
Table 1. Paired Samples Statistics

\begin{tabular}{|c|c|c|c|c|c|}
\hline & & Mean & $N$ & $\begin{array}{c}\text { Std. } \\
\text { Deviation }\end{array}$ & $\begin{array}{c}\text { Std. Error } \\
\text { Mean }\end{array}$ \\
\hline $\begin{array}{c}\text { Interval training } \\
\text { at 50m freestyle } \\
\text { swimming }\end{array}$ & Pretest & .6989 & 18 & .31775 & .07489 \\
\cline { 2 - 6 } & Postest & .5228 & 18 & .20562 & .04847 \\
\hline
\end{tabular}

The output data above explains that the acquisition of the average value to the pretest group 0.6989 while the posttest 0.5228 on the number of respondents 18 swimming athletes. This shows that before being given treatment the score was greater than after being given training namely $0.6989>0.5228$ so it can be concluded that there are differences in endurance and speed of swimming time after being given interval training in freestyle swimming. This data is strengthened by the results of the correlation test (Paired Samples Correlations) which are broken down in the following table 2:

Table 2. Paired Samples Correlations

\begin{tabular}{|c|c|c|c|c|}
\hline & & $N$ & Correlation & Sig. \\
\hline $\begin{array}{c}\text { Interval training at } 50 \mathrm{~m} \\
\text { freestyle swimming }\end{array}$ & $\begin{array}{c}\text { Pretest \& } \\
\text { Postest }\end{array}$ & 18 & .651 & .003 \\
\hline
\end{tabular}

The data shows that the correlation coefficient (Correlation) 0.651 with a significance value (Sig.) Of 0.003 . because the significance value 0.003 <probability 0.05 , it can be concluded that there is a relationship between the results of the pretest and posttest. The results of the Paired Samples Test output are broken down in the following table 3 .

The results of the Paired Samples Test table are known by Sig. (2-tailed) is $0.007<0.05$ then Ho is rejected and Ha is accepted that there is a difference in athlete's swimming time after being given freestyle swimming interval training so it can be concluded that there is an increase in athlete's freestyle swimming time after being treated.

Table 3. Paired Samples Test

\begin{tabular}{|c|c|c|c|c|c|c|c|c|c|}
\hline & & \multicolumn{5}{|c|}{ Paired Differences } & \multirow{3}{*}{$\mathrm{t}$} & \multirow{3}{*}{ df } & \multirow{3}{*}{$\begin{array}{l}\text { Sig. } \\
\text { (2-tailed) }\end{array}$} \\
\hline & & \multirow{2}{*}{ Mean } & \multirow{2}{*}{ Std. Deviation } & \multirow{2}{*}{$\begin{array}{l}\text { Std. Error } \\
\text { Mean }\end{array}$} & \multicolumn{2}{|c|}{$\begin{array}{l}\text { 95\% Confidence Interval of } \\
\text { the Difference }\end{array}$} & & & \\
\hline & & & & & Lower & Upper & & & \\
\hline $\begin{array}{l}\text { Interval training at } \\
50 \mathrm{~m} \text { freestyle } \\
\text { swimming }\end{array}$ & $\begin{array}{l}\text { Pretest - } \\
\text { Postest }\end{array}$ & .17611 & .24115 & .05684 & .05619 & .29603 & 3.098 & 17 & .007 \\
\hline
\end{tabular}




\section{Discussion}

Overall endurance and athlete's time has increased after the freestyle swimming interval training was conducted. This condition was achieved through swimming training conducted by 16 meetings. Every time the meeting is done swimming exercises repeatedly on a continuous basis both feet, hands, and overall coordination until the athlete reach the maximum ability and VO2. The exercise is carried out with movements that focus on one-handed, second-hand movements and followed up with foot movements. The exercises are carried out separately in each movement and followed by a full coordination movement exercise in each style. The duration of the exercise is applied in stages $4 \mathrm{x}$ 20m, 25m, 50m, 100m, 200m, 300m, 400m, 500m. Each session was carried out cross-style training but was more focused on freestyle. After the end of the exercise, a sprint is performed to find out the time achieved during the exercise. the training and sprint mileage starts from $20 \mathrm{~m}$, $25 \mathrm{~m}, 50 \mathrm{~m}, 100 \mathrm{~m}$, to $200 \mathrm{~m}, 400 \mathrm{~m}$ to form a multilevel mileage habit. Intermittent sprint training will contribute to energy derived from resources that stimulate heart rate and respiratory rate so that it can increase the capacity for aerobic metabolism [7], [19]. Sprint implementation for each distance traveled during training is expected to have a positive impact on increasing 50m swimming time of the prediction that the habits carried out during training at a longer distance will make it easier for athletes to reach with the shortest possible time.

During the sprint, 1-2 minutes are recovered. The recovery interval (relief interval) is the rest period between work intervals and between sets. The recovery process will occur at rest intervals. During recovery, the energy requirements are greatly reduced, but oxygen consumption continues at fairly high levels for some time. Oxygen consumption during recovery is used to provide energy so that it can improve the condition of the body as before exercise, including replenishing energy reserves that have been empty [18].

The results of the evaluation during the training process are known to increase and sometimes decrease. This can be seen during the sprint at the end of the exercise. This condition occurs because of body fatigue due to repetitive exercise processes. The trainer's effort to overcome the fatigue is done to improve physical conditions on land in the form of running, push ups, sit ups, back ups, full ups, squat thrust, agility, flexibility and weight training that supports swimming. This exercise needs to be done so that recovery occurs, Buchheit, Al, et al [20] stated that active recovery was beneficial in swimming. Even physical exercise can offer stimulus for increasing athletic strength and endurance [15].

During the interval, training the focus of the training is not only on the achievement of the duration of time but also on the improvement of the overall freestyle swimming technique. Interval training was carried out 16 times with physical training on the ground for eight times. Exercises are done to improve performance and muscle strength. After the overall training the final posttest was measured, the 50-meter freestyle swimming. The measurement results show that there is an influence of interval training conducted on the time obtained. This can be seen from the higher pretest data compared to the results of the posttest which shows the achievement of the swimming force of the free style $50 \mathrm{~m}$ faster. Obtaining a score after being given training for 52 seconds and a score before being given a mean training of 69 seconds, die an increase in the mean of 17 seconds.

This improvement still needs to be done because $50 \mathrm{~m}$ freestyle swimming is taken with the fastest time of 32 seconds, whereas previous studies have reached the best time of 30 seconds / 50m [21], trainers need to explore other factors that can increase swimming time such as motivation factors. The success of interval training requires a very high level of subject motivation [22] so strengthening intrinsic and extrinsic motivation in athletes must be maintained and need to be improved as one of the factors that can make a positive contribution to the addition of 50m swimming time. Even a high volume and intensity training program is an important component for an athlete [6] and needs to be done at subsequent interval programs. Increasing swimming time in national-level competitions should be an intrinsic and extrinsic motivation for swimmers and coaches so that the 30 -second / 50m time requirement for female athletes and 27 seconds / 50m for male athletes can be achieved as expected.

\section{Result}

This study concludes that there is a correlation between interval training and increased freestyle swimming time at a distance of $50 \mathrm{~m}$. The training was carried out 16 times with distance training focused on one-handed movements, both hands, leg movements and overall coordination of movements. Cross training in each style is also carried out but remains dominant in the freestyle. The training distance will increase from $25 \mathrm{~m}, 50 \mathrm{~m}, 100 \mathrm{~m}$ to $400 \mathrm{~m}$. Practice swims exercises repeatedly that end with a sprint and recovery between each distance or set after the exercise. The training is also equipped with physical training in the form of running, push ups, sit ups, back ups, full ups, squat thrust, agility, flexibility and weight training that supports swimming. Increased time will make a positive contribution to the achievement of time to become a National-Level Competition nominee, provided that it continues the training session intensely with additional training mileage.

\section{Acknowledgment}

We would like to express our special thanks and 
gratitude to our rector IAIN Curup (Dr. Rahmad Hidayat, M.Ag., M.Pd), Director of the Postgraduate University of Indonesian Education (Prof. Dr.Syihabuddin, M.Pd) and Head of sports education study program at the Indonesian university of Education (Dr. Amung Ma'mun, M.Pd) along with his staff who gave us support to carry out this extraordinary project. Secondly, we would also like to thank Sofwan, M.Pd.Kons who helped us a lot in finalizing this project within the limited time frame.

\section{REFERENCES}

[1] W. Atkins, "Interval Training," Gale Encycl. Fitness. Detroit Gale, pp. 475-477, 2012.

[2] J. Daniels, N. Scardina, and A. West, "Interval Training and Performance,” Sport. Med., vol. 334, pp. 327-334, 1984.

[3] G. Rodas, L. Ventura, J. A. Cadefau, and Â. J. Parra, “A short training programme for the rapid improvement of both aerobic and anaerobic metabolism,” Eur. J. Appl. Physiol. 82(5-6), 480-486., pp. 480-486, 2000.

[4] R. Baekkerud, , F. H., Solberg, F., Leinan, I. M., Wisloff, U., Karlsen, T., "Comparison of Three Popular Exercise ‘ O," pp. 491-498, 2016.

[5] P. B. Laursen and D. G. Jenkins, "The scientific basis for high-intensity interval training,” Sport. Med., vol. 32, no. 1, pp. 53-73, 2002.

[6] P. B. Laursen, "Training for intense exercise performance: high-intensity or high-volume training ?," Scand. J. Med. Sci. Sports, vol. 20, pp. 1-10, 2010.

[7] J. D. M. A. C. Dougall et al., "Muscle performance and enzymatic adaptations to sprint interval training," J. Appl. Physiol., pp. 2138-2142, 2018.

[8] J. Simoneau, G. Lortie, M. R. Boulay, M. Marcotte, M. Thibault, and C. Bouchard, "Applied Physiology Effects of two high-intensity intermittent training programs interspaced by detraining on human skeletal muscle and performance,” Eur. J. Appl. Physiol. Occup. Physiol. 56(5), 516-521., pp. 516-521, 1987.

[9] W. Kübler, "Book Reviews. Human cardiovascular control:," in Continuing Medical Education, 2nd Editio., Robert Ginsburg and Herbert J. Geschwind, Ed. Futura Publishing Company, Inc., Mount Kisco, NY, 1993, p. 98.
[10] J. A. Hawley, K. H. Myburgh, T. D. Noakes, and S. C. Dennis, "Training techniques to improve fatigue resistance and enhance endurance performance,” J. Sports Sci., no. July 2013, pp. 37-41, 2010

[11] P. B. Laursen and D. G. Jenkins, “Optimising Training Programmes and Maximising Performance in Highly Trained Endurance Athletes The Scientific Basis for High-Intensity,” no. May, 2014.

[12] R. C. Hickson, J. M. Hagberg, A. A. Ehsani, and J. O. Holloszy, "Time course of the adaptive responses of aerobic power and heart rate to training.," Med. Sci. Sports Exerc., vol. 13, no. 1, pp. 17-20, 1981.

[13] C. Foster, "Changes VO2max and running performance with training,” Eur. J. Appl. Physiol. Occup. Physiol. · Novemb. 1978, 2016.

[14] B. R. Londeree, "Effect of training on lactate/ventilatory thresholds: a meta-analysis,” Med. Sci. Sport. Exerc., vol. 29, no. 6, pp. 837-843, 1997.

[15] S. H. Costill, D. L., Flynn, M. G., Kirwan, J. P., Houmard, J. A., Mitchell, J. B., Thomas, R., \& Park, "Effects of repeated days of intensified training on muscle glycogen and swimming performanc," Med Sci Sport. Exerc. 20(3), 249-254, 1988.

[16] E. O. Acevedo and A. H. Goldfarb, "Increased training intensity effects on plasma lactate, ventilatory threshold, and endurance,” no. November 1989, 2017.

[17] H. Hartini, "Physical Development and Body Image of Teenagers,” Islam. Couns. J. Bimbing. Konseling Islam, vol. 1, no. 02, pp. 27-54, 2017.

[18] E. L. Fox, R. W. Bowers, and M. L. Foss, The physiological basis for exercise and sport., no. Ed. 5. Brown \& Benchmark, 1993.

[19] A. R. Harmer et al., "Skeletal muscle metabolic and ionic adaptations during intense exercise following sprint training in humans,” J. Appl. Physiol., pp. 1793-1803, 2018.

[20] M. Buchheit, Æ. H. Al, A. Chivot, Æ. P. Marie, S. Ahmaidi, and $Æ$. P. B. Laursen, "Effect of in- versus out-of-water recovery on repeated swimming sprint performance,” Eur. $J$. Appl. Physiol. 108(2), 321-327., pp. 321-327, 2010.

[21] P. Morouço, K. L. Keskinen, J. P. Vilas-boas, and R. J. Fernandes, "Relationship Between Tethered Forces and the Four Swimming Techniques Performance," J. Appl. Biomech. 2011, 27, 161-169, 2011.

[22] M. J. Gibala, "High-intensity Interval Training: A Time-efficient Strategy for Health Promotion ?," Curr. Sport. Med. reports, 6.4 211-213., 2007. 